\title{
International Design Synthesis Exercise 2006: Design of an Interceptor UAV
}

\author{
Paul Roling* \\ Delft University of Technology, Faculty of Aerospace Engineering, Delft, the Netherlands \\ Richard Cooper ${ }^{\dagger}$ and Richard Curran ${ }^{\ddagger}$ \\ Queens University Belfast, Northern Ireland UK
}

\section{Introduction}

Universities are tasked to prepare their students for a career in the society of the future. Students that start their education now will enter the labour market in the beginning of the 2010s and will stay active until at least the 2050s. Based on the observations given above, it is expected that more and more design projects will have an international nature. In response to this need, two aeronautical schools with a long standing working relationship - Delft University of Technology (TUD) and Queen's University Belfast (QUB) - conceived the idea to perform an international design exercise based on the existing Design-Synthesis Exercise (DSE) as run in Delft since 1999. ${ }^{1-3}$ Instead of developing a student exchange programme between the two universities, $3^{\text {rd }}$ and $4^{\text {th }}$ year students from both universities are selected to conduct a joint design synthesis exercise, with the support of staff on both sides. Whilst there are many interesting challenges with respect to such an international exercise, as can be found in Ref. 3 , this paper will concentrate more on the assignment itself and the actual design aspects.

Whilst air travel is one of the safest ways to travel across the world, a number of dangers are still present, and in order to keep air travel safe there is an everlasting search to improve and maintain safety. One very current issue in aviation is the intercepting, escorting and observing of civil aircraft in distress, especially aircraft which have lost communication or have problems with passengers or systems such as the landing gear. Current practice in these situations is the scrambling of fighter aircraft. The aim of the assignment for 2006 was thus to produce a preliminary design of an Interceptor Unmanned Aerial Vehicle (IUAV) as a viable and more efficient alternative to this current solution. The Unmanned Aerial Vehicle should be able to intercept, communicate with and observe airliners, while being reusable, autonomous and remote controlled and cost approximately $€ 1$ million.

The international design synthesis exercise team for 2006 consisted of D.E. Crummey, G.J. Davies, J.W.W.E. McCartan, S.M. McGuinness, O.P. O’Loan and G.M.T Winters from Queen's University of Belfast (QUB) and J.L.G. Bonten, G. Gielen, B. Lubbers, G.J.J.M. Pauwels and J.G.R. Verbeke from the Delft University of Technology (TUD)

\section{Requirements}

The task put upon the design team is to produce a preliminary design of an IUAV. Therefore, a list of requirements has to be found to obtain all criteria the IUAV needs to comply to. The most important requirements the IUAV needs to satisfy are set by the assignment. These are divided in several categories:
A. Design requirements
Unit production cost: $\sim 1$ million euros
Mission requirements:
Time to take off $<5$ minutes
Maximum flight range $>1800 \mathrm{~km}$

\footnotetext{
${ }^{*}$ Lecturer/Associate researcher

${ }^{\dagger}$ Professor

${ }^{\ddagger}$ Professor, AIAA associate member
} 
Maximum endurance $>3$ hours

Ceiling > FL420

Maximum Cruise Speed $>$ Mach 0.85

Disabling a commercial airliner, possibly by sacrificing the UAV

\section{B. Payload requirements}

Near 360 x 180 degree (multiple) camera view

Autonomous and remote controlled flight

High stability and recoverability for flying in close formation with aircraft

On board transponder / Traffic detection and collision avoidance system.

\section{Secondary requirements}

Operational concept for EU coverage, including estimations of interception times.

Assessment of alternative uses for this vehicle (military operations, civil operation etc.)

\section{Sustainability}

The UAV should be proven to have lower costs, lower environmental impact and be better suited for an interception mission than a fighter aircraft, as the F-16.

Although the precious requirements dictate a large part of the direction taken in the design process, these are not the only driving factors. In order to be able to perform the task of intercepting, observing and escorting airliners in a satisfactory manner, one must be able to partake in air traffic in a safe and sustainable way. It would indeed be a paradox to produce an aircraft with the task to benefit the safety of aviation, which itself is a danger to others on land and in the sky; hence the aircraft should also comply with all applicable airworthiness requirements and appropriate laws.

\section{Concept study}

After having obtained all requirements, concepts are developed and a trade-off is performed between four conceptual designs, which have been developed and are displayed in Figure 1. These are:

- A supersonic conventional concept

- A delta wing with canard concept

- A subsonic conventional concept

- A blended wing body concept

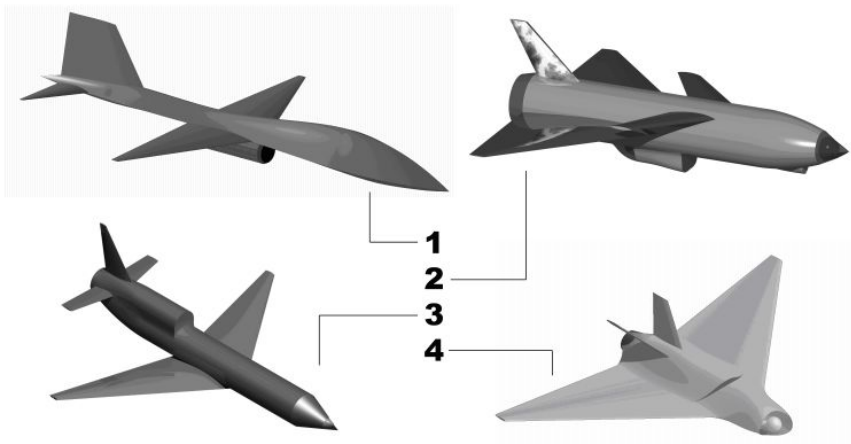

\section{A. The supersonic conventional concept}

This concept is able to fly at supersonic speeds,

Figure 1: The four conceptual designs

thereby reducing the time needed to intercept an aircraft. The general layout resembles that of a conventional aircraft with a classic tail and the engine is located at the bottom of the fuselage, as is the air intake. It takes-off from a launch platform using a rocket and is recovered by parachute. Cameras are placed in the nose to ensure a 360x180 degree view to the front of the IUAV.

\section{B. The delta wing with canard concept}

This concept flies at supersonic speeds. It has a delta wing, making it more efficient in the transonic regions compared to a conventional wing plan and reducing the wave drag in the supersonic regime. It has canards placed above and in front of the wing for stability and manoeuvring, making the IUAV highly manoeuvrable. The engine is at the back of the fuselage and the intake at the bottom of the IUAV. Take-off and landing are conventional using a landing gear. 
One camera pod, having a 360x180 degree view, is located in the front and the other aft of the air intake, giving an 180x90 degree view to the back. Also, a forward-looking infrared camera (FLIR) is placed in the nose. This is fixed and will always give the pilot on the ground a forward view.

\section{The subsonic conventional concept}

This concept flies at low transonic speeds (below Mach 1) and has a conventional layout with vertical and horizontal tail planes. The engine is located high up at the rear of the fuselage and has the intake on the top. Also, it has a landing gear, making conventional take-offs and landings possible.

There is one camera in the nose, giving the IUAV a 360x180 degree view, and one in the tail, enabling the operators to look aft of the vehicle. The strong point of this concept is it's ease of design and the proven technology used.

\section{The blended wing body concept}

This concept also flies at low transonic speeds. Its wing is located at the back and it has a V-tail. The wing and body are blended, making the IUAV aerodynamically more efficient. The engine is located in the rear of the fuselage and has its intake on top. It uses a rocket-assisted take-off and parachute recovery.

Both cameras are placed in the nose with one looking forward, giving a 360x180 degree forward view, and one looking down and back, giving it an aft view at an angle of about 10 degrees.

When the conceptual design phase is completed, a choice is made on which concept moves into the preliminary design. In order to make this decision, a trade-off study is performed. Each concept discussed above exhibits its own benefits and drawbacks. The trade-off has distinguished between the concepts and determined the final concept to be developed.

\section{Supersonic dilemma}

The supersonic dilemma has run across the entire project, the designs and through many decisions taken. Was the IUAV to cross the sound barrier or not? For the final design it was decided that Mach 1 would not be a design goal. As the mission of the IUAV is fast interception, a supersonic plane has an advantage due to its higher maximum speed. The calculated interception distances traveled after take-off, which are shown in table 1, show that differences between high subsonic and low supersonic designs are very limited. This limited difference is mostly due to the fact that the time a supersonic design is able to fly above Mach 1 is limited by the IUAV having to climb to appropriate altitudes before being able to attain supersonic speeds.

\begin{tabular}{|l|l|l|}
\cline { 2 - 3 } \multicolumn{1}{c|}{} & Supersonic design & Subsonic design \\
\hline $15(\mathrm{~min})$ intercept time & $140 \mathrm{~km}$ & $140 \mathrm{~km}$ \\
\hline $30(\mathrm{~min})$ intercept time & $440 \mathrm{~km}$ & $390 \mathrm{~km}$ \\
\hline
\end{tabular}

Table 1: Intercept distances for different intercept times

A supersonic design would still have the advantage of being able to gain more quickly on an airliner, even one flying away from the IUAV, but in order to assure an infallible and fast interception throughout Europe at least 2 or 3 IUAVs on different locations need to be scrambled to intercept a single target. This insures that at least one IUAV will always be able to intercept the aircraft within the specified intercept time independent of the target's manoeuvres. Hence the need for supersonic speeds can be disregarded.

\section{The Hyperion design}

The trade-off was done with a table showing each concept's strengths and weaknesses, and resulted in the blended wing body as the winning concept, with several strengths from other concepts incorporated into it. The resulting concept is called the Hyperion. Hyperion is a Greek Titan and is considered the 'God of Observation' and is the brother of Theia the 'Goddess of Sight'. This was deemed an appropriate and dignified name for the IUAV, as observation is its main task. Here an overview of the final design is given. 
The Hyperion is a single-engine UAV with characteristics, which make it particularly suitable for the interception mission. It encompasses systems that allow the Hyperion to fly autonomously as well as remote controlled. Telemetry and all other data transfer between ground station and IUAV will be by UHF/Ku-band radio link. This link will provide enough bandwidth to accommodate the data that needs to be transferred. Cameras, placed in the front and rear of the IUAV, offer proper views of the intercepted aircraft in all flight interception scenarios, using

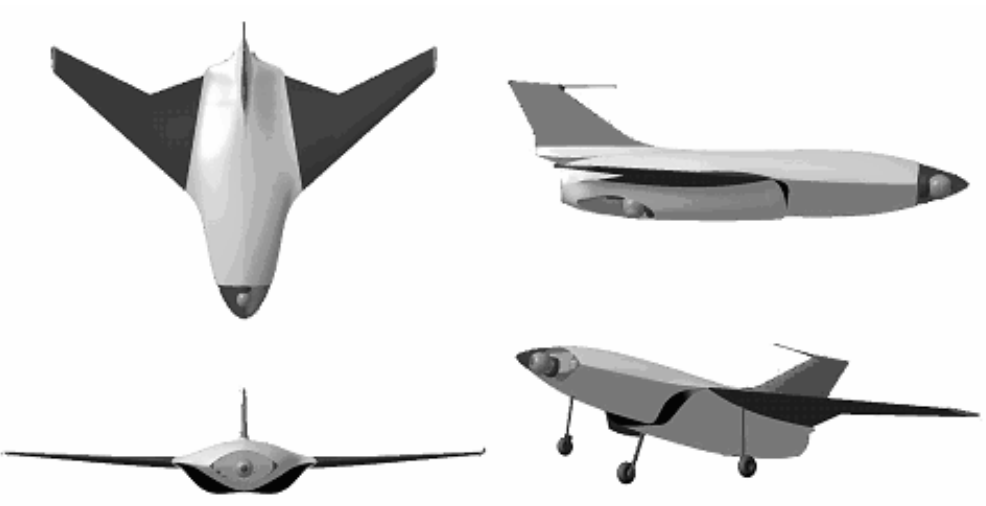
interception regulations that follow from ICAO regulations. A landing gear is incorporated in the design, as it will increase the flexibility. Four views of the Hyperion can be seen in Figure 2. The Hyperion will take-off in less time than a fighter aircraft, when scrambled. It will then accelerate to an optimal climb speed, after which an optimal climb is initiated in the direction of the aircraft to be intercepted. At cruising altitude the Hyperion will level out, accelerate to maximum cruise speed and intercept the aircraft. Once arrived at the aircraft it will perform its mission, observation or escort, and subsequently land by using the instrument landing system (ILS).

\section{Layout and systems}

After performing investigations into the aerodynamic and stability characteristics of the Hyperion, a final wing plan and control surface sizing is found, the parameter values in Table 2 are known and Hyperion's planform, as is shown in Figure 2, is determined. The Hyperion must be able to fly autonomously and be remote controlled and for this it has to have advanced avionic systems on board, which are mostly commercial of the shelf (COTS) products and are located in modules in the front of the fuselage. Fuel is located in the wings and in several tanks in the fuselage and the landing gear is also located in the fuselage. An overview of these systems can be found in Figure 3. Other important aspects are discussed below.

\begin{tabular}{|l|l|}
\hline Parameter & Value \\
\hline Aspect ratio [-] & 4 \\
\hline Wing area $\left[\mathrm{m}^{2}\right]$ & 3.78 \\
\hline Wingspan [m] & 3.89 \\
\hline Mean wing chord [m] & 1.04 \\
\hline Quarter chord sweep [ $\left.{ }^{\circ}\right]$ & 40 \\
\hline Taper ratio [-] & 0.16 \\
\hline Thickness/chord ratio [-] & 0.1 \\
\hline Fuselage length [m] & 2.65 \\
\hline
\end{tabular}

Table 2: Parameter values of the Hyperion

\section{A. Take off and recovery method}

The advantage of a rocket assisted take-off (RATO) is a reduced time needed to get the IUAV airborne. This will not necessarily lead to a greater intercept distance, as is shown in chapter VII. The advantage of a parachute recovery is the flexibility in getting the IUAV safely onto the ground at any location, not only airfields, especially in case of an emergency as this would negate tre requirement of first flying it to an airfield. The downsides of the RATO and parachute landings are that they require extra support equipment, such as a take-off and recovery vehicle, which increases the operational costs. Thus it was decided that the basic Hyperion design will only have a landing gear to decrease turn-around time and make the IUAV easier to operate by reducing the need for extra support equipment. It also means that the Hyperion can refuel at any airfield and commence operation again where a UAV with a parachute and RATO would need service at designated stations before it can be operational again which would mean a reduction in speed and flexibility. 


\section{B. Air intake}

Hyperion's air-intake is located between the fuselage and the bottom of each wing, as this reduces drag and prevents airflow problems with the aircraft flying at high angles of attack and also has a good efficiency in the speed regime that the UAV will operate in.

\section{Cameras}

The camera is placed in such a way that is has as much coverage as possible, whilst being positioned inside the airframe to produce as little drag as possible. The first observation pod is located in the nose, made from Lexan, giving a $180^{\circ} \times 360^{\circ}$ view to the front. The second observation pod is located aft of the right air-intake,

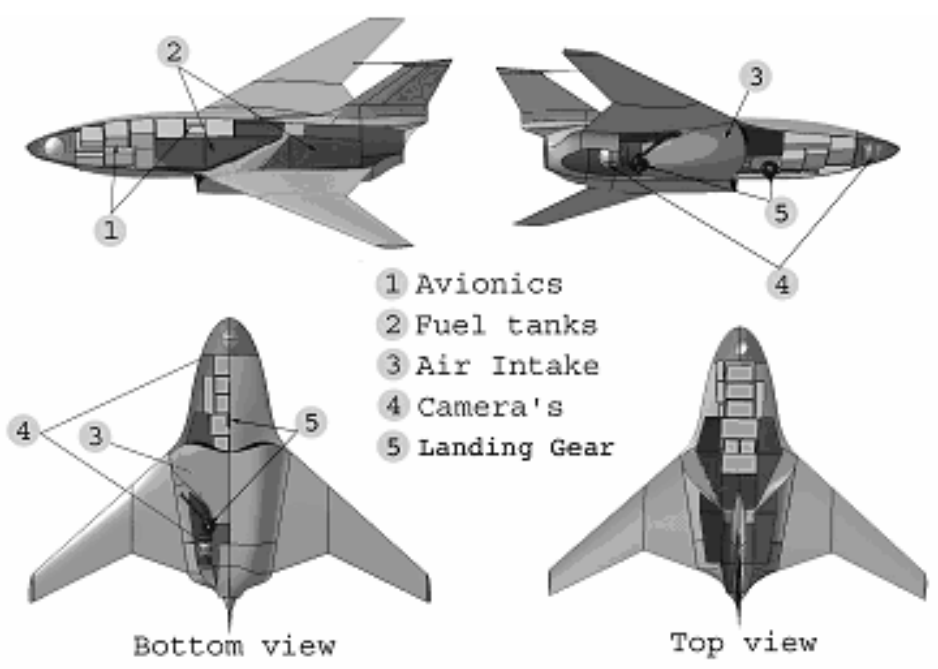

Figure 3: System layout of the Hyperion which makes it possible to observe the aircraft when flying in front of them during standard interception operations. The FLIR camera in the nose is fixed, always giving a controller on the ground a view in the direction of flight, even when the forward camera pod is directed away. The optical suit consists of two IAI Taman MiniPOPs and a ThermoVision EVS1000 FLIR-camera. The MiniPOP incorporates visible and infrared light cameras to enable operations in day- and nighttime.

\section{Laser-rangers}

Laser-rangers are installed in the camera gimbals to measure the distance between the Hyperion and the target aircraft with high accuracy, which is needed for a safe escort whilst still enabling the IUAV to fly close to the intercepted aircraft without sacrificing safety.

\section{E. Autonomy}

It is very important that the IUAV is able to fly autonomously as this greatly increases the flexibility and speed of the interception. The specific issues of a remotely and/or autonomously operated vehicle increase the need of specialized equipment compared to conventional UAVs, which operate under continuous monitoring of ground control, and manned aircraft. Therefore systems to improve situational awareness that are normally not present on UAVs are necessary to ensure safe autonomous flight of the Hyperion design.

\section{F. Communication.}

Data transmission of flight data and camera images is done via line-of-sight radio-link. The range of the Hyperion will be $360 \mathrm{~km}$ from the launch site, however another IUAV can act as a relay station, extending the range. Satellite communication is possible but omitted in this design, mainly due to high costs or volume of the antenna systems.

\section{G. Safety}

Sufficient flight control systems are present in the Hyperion to ensure safe autonomous flight but for safety reasons the IUAV must be able to recover automatically in the event of a loss of the communication link. This has been considered and a proper procedure has been established for a safe recovery. 


\section{Performance and Operational concepts}

The Hyperion complies with all requirements set upon it, such as the performance characteristics shown in Table 3.

The IUAV should be able to disable an airliner but as there are some legal boundaries which limit the use of offensive weaponry and thus this ability. To still be able to perform this

\begin{tabular}{|l|l|}
\hline Parameter & Value \\
\hline Maximum range [km] & 2,580 \\
\hline Maximum endurance [hrs] & 3.5 \\
\hline Ceiling [ft] & 50,000 \\
\hline Maximum cruise speed [-] & Mach 0.9 \\
\hline Unit production cost [€] & $1,325,000$ \\
\hline
\end{tabular}

Table 3: Performance of the Hyperion requirement, the Hyperion can use its laser-ranger to fly into a hostile airplane with great accuracy, sacrificing itself.

For the coverage of the European Union (EU) three scenarios were taken into account of which the most economically and politically viable is the scenario where 23 ground stations are required, which is shown in Figure 4. At each ground station at least 3 IUAVs are based, each with an interception range of $360 \mathrm{~km}$ (within communications range).

The Hyperion is designed to perform quick reaction alert (QRA) missions, but it can also be used for other (para)military, public and commercial applications, such as search and rescue (SAR) or surveillance operations. It can be used for combat reconnaissance and support, such as target designation or damage assessment and in its SAR capability, the Hyperion is particularly apt in performing time-critical search assistance and its quick reaction time and high speed allow for an unmatched time to target. Surveillance applications can include detection and mapping of forest fires, performing border patrols, monitoring disaster or pollution areas or smuggling activities.

\section{Conclusions and recommendations}

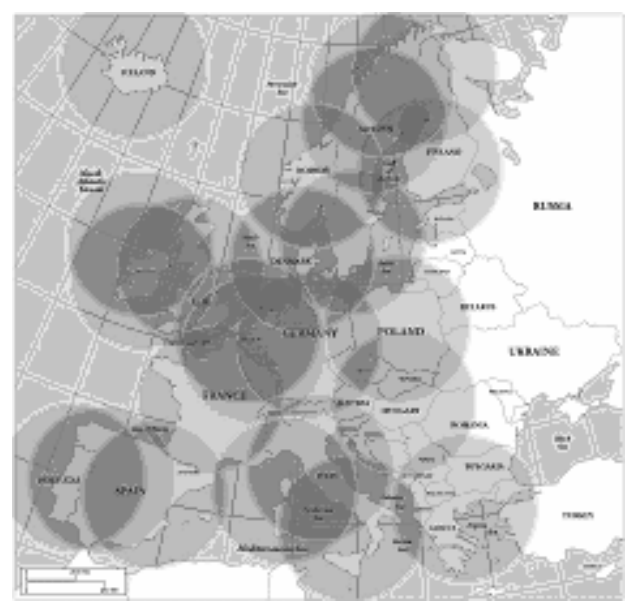

Figure 4: EU coverage concept

The Hyperwork's Hyperion, a single engine IUAV that is able to fly with a high degree of independence from direct operators, is a viable solution for cheap and fast interception of airliners. It has gimbals on board which carry cameras and laser-rangers and are able to accurately observe the intercepted airliner and determine and maintain distance to that airliner. An UHF/Ku- band radio data link enables the data transfer of telemetry and video images between IUAV and ground station.

All requirements set upon the IUAV are met or exceeded with its cruise speed of Mach 0.9, its operational ceiling of $50,000 \mathrm{ft}(15.2 \mathrm{~km})$, range of $2580 \mathrm{~km}$ and its endurance of 3.5 hours. The Hyperion costs around $€ 1,325,000$ for an approximation of 202 sold units and from the performance characteristics it is clear that the Hyperion design can be regarded as a good foundation for further detailed design.

Since the Hyperion is only designed in a preliminary stage, further research and design is necessary. Two topics that need to be researched to improve the economic viability of the Hyperion design are the transportation of explosives through civil airspace and market research into search and rescue and disaster area assessment.

Furthermore, an increase in the use of composites such as composite wings would be beneficial as composite wings decrease the structural weight and the risk of fatigue. A last recommendation is to further optimize and more accurately determine the aerodynamic characteristics of the Hyperion by performing wind tunnel tests and Computational Fluid Dynamics (CFD) calculations. 


\section{References}

${ }^{1}$ Brügemann, V., Brummelen, H. van, Melkert, J., Kamp, A., Reith, B., Saunders-Smits, G.N., Zandbergen, B.: An example of active learning in Aerospace Engineering. Research and Practice of Active Learning in Engineering Education, Editors: E. de Graaff, G.N. Saunders and M.R. Nieweg, Amsterdam University Press, 2005, p. 156-164.

${ }^{2}$ Melkert, J.A., Gibson, A., Hulshoff, S.J., “An International Design-Synthesis Exercise in Aerospace Engineering”, Global Journal of Engineering Education, Volume 7, Number 1, 2003, pp. 121-130

${ }^{3}$ J.A. Melkert (editor), Delft Aerospace Design Projects 2006 and earlier editions, Het Goede Boek, Huizen, 2006.

${ }^{4}$ G.N. Saunders-Smits, P.C. Roling, J.A. Melkert, R. Curran, R.K. Cooper, J. M. Early, Crossing border - 6 years of international aerospace student design projects. 